\title{
Monitoramento e avaliação baseados em Sensometria para cursos de educação a distância
}

\author{
Lucivane Aparecida Marchiori GARCINDO ${ }^{1}$
}

Eric Batista FERREIRA ${ }^{2}$

\footnotetext{
${ }^{1}$ Pedagoga, especialista em Educação e em Psicopedagogia. Autor correspondente: lu.marchiori @gmail.com ${ }^{2}$ Professor Adjunto III, Departamento de Ciências Exatas, Universidade Federal de Alfenas, Unifal-MG
}

Recebido em: 24/05/2013 - Aprovado em: 30/07/2013 - Disponibilizado em: 15/08/2013

RESUMO: A educação a distância no Brasil cresce a cada dia. A Coordenação Pedagógica desses cursos tem, entre outras atribuições, a função de garantir a qualidade dos trabalhos realizados. Este artigo propõe um modelo de monitoramento e avaliação da qualidade e melhoria contínua para cursos a distância, baseado em análise sensorial. O funcionamento desse modelo é ilustrado com o estudo de três cursos. O Mapa de Preferência, uma das ferramentas estatísticas aplicadas a Análise Sensorial, se mostrou eficiente na identificação de pontos positivos e negativos nos cursos de pós-graduação Lato Sensu analisados.

Palavras-chave: Coordenação Pedagógica; Educação a Distância; Controle de Qualidade; Melhoria Contínua; Análise Sensorial.

\section{Sensometrics based monitoring and evaluation for distance learning courses}

\begin{abstract}
Distance education increases every day in Brazil. The Pedagogical Coordination of these courses have, among other things, the function of guaranteeing the quality of the work performed. This paper proposes a framework for monitoring and evaluation of quality and continuous improvement for distance learning courses, based on sensory analysis. The operation of this model is illustrated with the study of three courses. The preference mapping, one of the statistical tools applied to Sensory Analysis, proved effective in identifying strengths and weaknesses of the postgraduate Lato Sensu courses analyzed.
\end{abstract}

Keywords: Pedagogical Coordination; Distance Education; Quality Control; Continuous Improvement; Sensory Analysis.

\section{INTRODUÇÃO}

\begin{tabular}{l} 
A Educação a distância ${ }^{1} \quad($ EaD) \\
caracteriza-se de várias maneiras mas, \\
\hline 1
\end{tabular}

O termo Educação a Distância será usado desta maneira, sem crase, em principalmente pela troca de conhecimentos a distância por meio de recursos tecnológicos consonância com a padronização de escrita feita pelo Ministério da Educação - Secretaria de Educação a Distância (MEC/SEED) (DOU, 2002). 
e outros, onde discente e docente estão separados no tempo e/ou espaço. Educação a distância é uma forma de ensino que possibilita a auto-aprendizagem, com a mediação de recursos didáticos sistematicamente organizados, apresentados em diferentes suportes de informação, utilizados isoladamente ou combinados, e veiculados pelos diversos meios de comunicação (BRASIL, 1998a). A EaD vem sendo muito estudada nos últimos anos. Dentro da Educação a distância, a modalidade mais ofertada no Brasil é a de cursos de Pós-Graduação em Especialização

Lato sensu.

Atuando como coordenadora pedagógica do departamento de Administração e Economia da Universidade Federal de Lavras, conclui que para gerir esses cursos é de extrema importância o papel da coordenação pedagógica. Dentre suas atribuições, destacam-se: conhecimento da história da $\mathrm{EaD}$, estudo constante de Leis, elaboração de projetos de curso, assessorar os docentes, mediação entre docentes e discentes, seleção e acompanhamento dos tutores $^{2}$, verificação do trabalho da secretaria, apoio à equipe de informática, auxilio na redação dos textos acadêmicos e elaboração de atividades avaliativas para a verificação da aprendizagem.

${ }^{2}{ }^{2} \mathrm{O}$ tutor é um elemento importante em muitos sistemas de EAD, sendo o principal responsável pelo processo de acompanhamento e controle do ensinoaprendizagem.

www.escolanet.com.br/dicionario/dicionario_t.html
Para tanto, o monitoramento e avaliação constante quando, por exemplo, os cursos de Pós-graduação em Especialização têm sua procura diminuída, na maioria das vezes seus coordenadores costumam fazer mudanças empíricas e reformulações drásticas, que muitas vezes levam à remoção de aspectos positivos e nem sempre logram êxito.

É importante que toda e qualquer mudança seja feita com informações confiáveis e sob métodos científicos. Para esse fim, o monitoramento e avaliação da qualidade e a melhoria contínua são fundamentais.

A investigação da qualidade pode ser feita com o auxílio de diversas ferramentas. Nesse estudo é proposto que o monitoramento e avaliação de cursos se baseie na percepção do discente, por meio de técnicas de análise sensorial.

A Sensometria é o conjunto de métodos estatísticos aplicados à análise sensorial. Nesse trabalho é realizado utilizando-se uma ferramenta da sensometria chamada Mapa de Preferência um estudo dos cursos do departamento de Administração e Economia Administração Rural, Gestão de Micro e Pequenas Empresas e Controladoria e Finanças Empresariais.

Desta forma o presente estudo realizou o monitoramento e avaliação de cursos a distância baseado na análise da percepção do discente, ou seja, análise sensorial. A partir do referido estudo, sugere- 
se que a referida análise seja responsabilidade da coordenação pedagógica e vise a melhoria contínua da qualidade.

Assim, os capítulos seguintes contemplam especificamente: uma Retrospectiva Histórica; aspectos da EaD; Legislação; Controle de Qualidade e Melhoria Contínua no ensino; Análise Sensorial na Educação. Propor o novo modelo de monitoramento e avaliação propriamente dito. Aplicar o modelo proposto no estudo de três cursos de pósgraduação Lato sensu a distância onde já atua uma coordenação pedagógica.

Um desafio, uma necessidade imperiosa dos tempos atuais, uma imposição a que não se pode fugir, envolta em diferentes concepções, a EaD é uma das soluções para a atualidade. As novas tecnologias de comunicação e informação como a televisão, o vídeo, a informática com a internet ganhando espaços cada vez maiores - sem desprezar os meios tradicionais de correio, telefone e postos pedagógicos organizacionais - convidam, se é que não exigem, um aproveitamento amplo de suas possibilidades em benefício da educação.

A educação a distância evoluiu através de diversas gerações e baseia-se num modelo educacional em que a Aprendizagem não tem limitações espaciais ou temporais. $\mathrm{O}$ cenário envolvente desta forma educacional parte do princípio que existe uma separação geográfica e/ou temporal entre o aluno e o professor, a utilização de tecnologia como veículo de distribuição e comunicação e, finalmente, o controle do nível de conhecimento adquiridos pelo próprio aluno (MUNDIM, 2006).

\subsection{Retrospectiva Histórica}

Por volta de 1850, agricultores e pecuaristas europeus aprendiam, por correspondência, como plantar ou qual a melhor forma de cuidar do rebanho. Esse é o começo do ensino a distância. Essa modalidade de ensino apareceu no Brasil, timidamente, no começo do século passado, também por correspondência (MARQUES, 2004).

Historicamente, o ensino a distância evoluiu através de diferentes gerações acompanhando o desenvolvimento tecnológico das telecomunicações, da informática e da internet. As tecnologias utilizadas aumentam progressivamente em número, complexidade e potencialidade, criando novos modelos de formação a distância. Essas evoluções segundo Mundim, podem ser agrupadas em três gerações:

Primeira Geração (1840-1970): Cursos por Correspondência. Neste caso a história do ensino a distância inicia-se em 1840, com cursos distribuídos por correspondência. Em meados do século XIX, estudo em casa, via correspondência, transformou-se em uma forma legítima de instrução, devido ao desenvolvimento de serviços postais baratos na Europa e nos 
Estados Unidos. Os instrutores passam a produzir textos, guias de estudo e outros materiais impressos que eram enviados pelo correio aos estudantes, os quais ganhavam créditos para concluir com sucesso as suas atribuições específicas.

Os cursos por correspondência, segundo Marques (2004), foram largamente usados até a metade deste século, sendo caracterizados por uma comunicação mínima entre aluno-professor, realizada de forma lenta e ineficiente pelo sistema postal tradicional.

\section{Segunda Geração (1970-1980):}

Universidades Abertas. Esta geração caracterizou-se por novos veículos de disseminação de conteúdo, como o rádio e a televisão, complementados com textos para leitura enviados por correspondência.

Um exemplo é a Universidade aberta Britânica. A Open University foi inaugurada em 1969, pelo Primeiro-Ministro Harold Wilson, e seus primeiros cursos foram oferecidos a partir de 1971. A Universidade estabeleceu sua sede no Walton Hall, campus criado na cidade de Milton Keynes, região da Inglaterra a cerca de 70 quilômetros ao noroeste de Londres. Desde o início, persistiu que a Universidade ganhasse credibilidade, tanto quanto uma universidade convencional. Ela deveria ser aceita e reconhecida no Reino Unido, tanto pelos estudantes quanto pelos políticos e acadêmicos acostumados com instituições tradicionais de ensino presencial. A palavra- chave para conquistar o reconhecimento da Universidade era "qualidade" (SANTOS, 2006).

$\mathrm{Na}$ fase do rádio e da televisão foi cunhado o termo Universidades do Ar. Esse nome foi inspirado no fato de que a emissora BBC (British Broadcasting Corporation) de Londres apresentaria os programas de televisão e de rádio que fariam parte dos cursos da Universidade. A primeira menção pública sobre a Universidade do Ar se deu no ano de 1963, em pronunciamento de Harold Wilson durante o período de eleições. Quando o Partido dos Trabalhadores chegou ao poder em 1964, formou-se um comitê Parlamentar, conhecido como comitê de conselheiros, para deliberar sobre a concepção do Projeto de Criação da Open University. Este comitê escreveu a proposta parlamentar para a Criação da Universidade do AR. A proposta estabelecia as primeiras diretrizes para o que seria um projeto ambicioso, desafiador e inovador, visando a uma maior disseminação do ensino superior no Reino Unido (SANTOS, 2006).

Com a popularização do rádio e da televisão, as informações passaram a chegar mais rapidamente, pois passam a ser levadas diretamente à casa do aluno, diminuindo a barreira da distância. No entanto no Brasil, a filosofia de ensino continuava sendo a de um curso por correspondência, visto que a única diferença era marcada por uma maior diversidade de material e facilidade em obtêlos. A comunicação continuava 
essencialmente unidirecional, muito escassa e lenta, já que ainda era realizada pelo sistema postal tradicional (MARQUES, 2004).

\section{Terceira Geração (1980-1990):}

Cassetes de vídeo, televisão. O início do uso de cassetes de vídeos e a proliferação das comunicações por satélites revelaram o papel da televisão no ensino a distância. Os conteúdos distribuídos por televisão ofereciam uma boa qualidade de imagem e som, e os cassetes de vídeo permitiam que os alunos assistissem às lições do curso a qualquer hora do dia e repetissem o conteúdo quantas vezes desejadas (MUNDIM, 2006).

No Brasil, fundações privadas e nãogovernamentais começaram a oferecer supletivo a distância na década de 70 , no modelo de teleducação (telecurso), com aulas via satélite complementadas por kits de materiais impressos. Nessa época, o país era considerado um dos líderes da modalidade, com os pontos fortes também no Projeto SACI e Projeto Minerva, que já capacitava professores com formação, apenas, em magistério. Entre 1988 e 1991, se deu a informatização e a reestruturação do Sistema de Teleducação, estabelecendo-se as diretrizes válidas até hoje. Foi já nesse contexto que, em 1995, o Departamento Nacional de Educação criou um setor destinado exclusivamente a EAD-CEAD (Centro Nacional de Educação a Distância) (MARQUES, 2004).

Desta forma, a educação a distância carecia de um meio de comunicação que possibilitasse uma interatividade mais intensa e rápida entre alunos e professores, já que aqueles obtidos por meio do sistema postal, rádio, vídeo cassete e televisão eram insatisfatórios. O telefone ajudou bastante, mas era (e ainda é) uma forma de comunicação muito cara, quando se considera que aluno e professor podem estar em partes diferentes do mundo, e ineficiente, sendo que o professor só pode atender um aluno de cada vez e de forma síncrona, ou seja, o telefone tem que ser atendido na hora que toca e não quando se tem tempo para atendê-lo (MARQUES, 2004).

Na quarta geração, Mundim apresenta as ferramentas mais atuais utilizadas no $\mathrm{EaD}$ hoje.

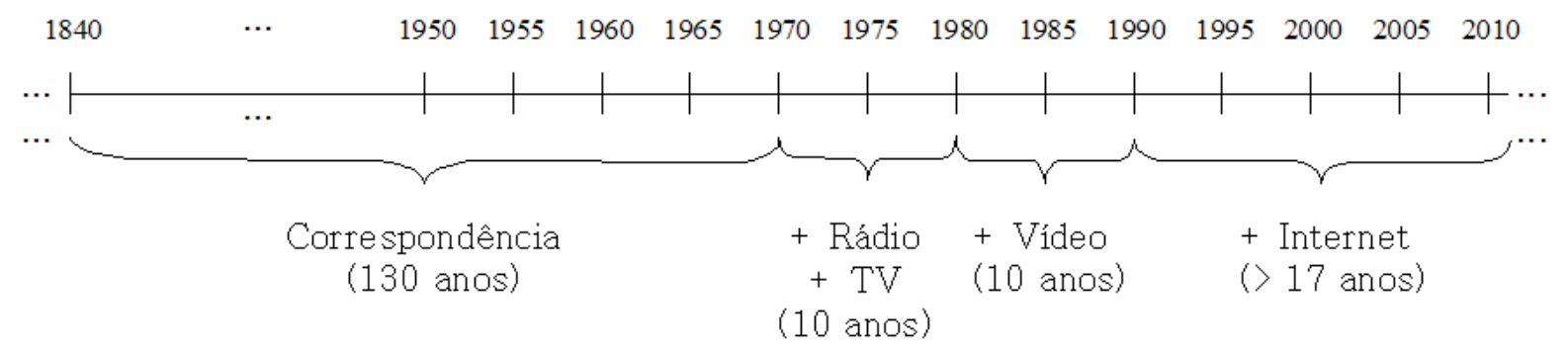

FIGURA 1 Linha do tempo da EaD no mundo, destacando-se os meios de comunicação utilizados. 


\section{Quarta geração (>1990):}

Computadores multimídia, interatividade, " $e$ -

Learning”. Os avanços na tecnologia digital criaram novas formas de interatividade que reformularam a educação e o modo como os alunos aprendem à distância. Neste sentido, $\mathrm{o}$ ensino a distância da quarta geração (EaD 4G) se apresenta com uma nova roupagem e está baseada nas novas tecnologias (Internet, computador, DVD). Segundo Mundim (2006), o emprego de novas tecnologias, num processo cinegético, amplia o potencial cognitivo do ser humano (seu cérebro e mente) e possibilita mixagens complexas e cooperativas, estimulando o aluno a ser autônomo, para conduzir o seu conhecimento no seu ritmo e conforme sua necessidade ou interesse. Quanto ao professor, este é levado a se capacitar e conhecer novas técnicas do processo ensino/aprendizagem, pois a tecnologia envolve novos conceitos de comunicação, diferentes dos conhecidos em um ambiente de aula presencial. Além disso, a EaD de quarta geração é uma metodologia de ensino que permite uma mediação síncrona e assíncrona entre técnicas instrucionais especiais e deferentes métodos de comunicação, principalmente por meios eletrônicos, assim como uma organização administrativa própria.

\subsection{Aspectos da EaD}

São conhecidas na literatura inúmeras vantagens do Ensino a Distância (não que sejam exclusivas da $\mathrm{EaD}$ ), destacadas a seguir.

- Flexibilidade no acesso a aprendizagem Amplia as possibilidades de escolha de local e horário de estudo e permite maior adaptação ao ritmo de aprendizagem do participante. Os materiais de aprendizagem estão disponíveis a todo o momento e são acedidos no local (casa ou trabalho) e à hora mais conveniente para o aluno, sendo, para muitos, a única forma de se integrar a um ambiente de formação.

- Economia de tempo - O aluno não necessita de viajar nem de interromper as suas atividades, podendo canalizar esse tempo para a aprendizagem.

- Capilaridade - Permite o acesso universal e o aumento da qualidade social no acesso à educação e a fonte de conhecimento.

- Competência - Desenvolve competência dando autonomia de estudos e organização do trabalho intelectual dos participantes.

- Inclusão - Possibilita atender grande número de pessoas, situadas em diferentes localidades, simultaneamente, sem deslocamento de casa ou do trabalho.

- Aprendizagem mais personalizada - Os conteúdos podem ser personalizados e o nível da aprendizagem expandido consoante às necessidades dos alunos e aos objetos a serem atingidos.

- Controle e evolução da aprendizagem ao ritmo do aluno - O aluno é responsável pela sua aprendizagem, decisão dos conteúdos a estudar e pela imposição do ritmo e da 
profundidade com que se pretende assimilar.

É impressionante o auge da educação a distância nos países durante as duas últimas décadas. Este crescimento quase explosivo obedece, por uma parte, ao fato real de que as demandas educacionais, que são cada vez maiores, de modo algum podem ser satisfeitas pelas modalidades tradicionais de ensino (GUTIERREZ; PRIETO, 1994).

A principal diferença entre modalidade de educação a distância e a presencial são as diversas ferramentas que o corpo discente, docente e escolar se apropriam. "O desafio essencial desta modalidade é o de estabelecer processos de instrução para levar a cabo, em grande escala, as funções de planejamento de instrução que o professor da aula realiza em pequena escala de maneira flexível" (GUTIERREZ; PRIETO, 1994).

A educação como um todo (não só a $\mathrm{EaD})$, também tem seus riscos, e é o que estes autores nos colocam a seguir.

$O$ fato de que a modalidade a distância esteja centrada não no professoreducador-que-desaparece, mas nos materiais de comunicação, que têm de ser previamente planejados, elaborados, validados e distribuídos, traz uma série de características que é preciso conhecer-se e saber aplicar pedagogicamente com muito mais eficácia e precisão do que na modalidade presencial. Caso contrário, os riscos são maiores e os fracassos poderiam ser irreparáveis. Eis alguns desses riscos:
1. ensino industrializado;

2. ensino consumista;

3. ensino institucionalizado;

4. ensino autoritário;

5. ensino massificante.

Cada um desses riscos será tratado a seguir.

1. Ensino industrializado - A produção de materiais de instrução está mais próximo dos métodos industriais do que dos processos de educação participativa. De fato, o que em educação a distância "parecia ser desejável em termos pedagógicos poderia não ser concretizável economicamente, pelo que é apropriado dizer que as economias recentemente industrializadas aplicam também métodos industriais na educação" (GUTIERREZ; PRIETO, 1994).

A experiência das últimas décadas demonstra que uma boa e massiva produção de materiais de instrução exige uma divisão de trabalho, economias de escala, controle de qualidade, uniformidade de distribuição, avaliação objetiva e algumas outras características que são típicas da produção industrial.

\section{Ensino consumista - A produção} industrial de materiais de instrução desencadeia como conseqüência, processos de venda e consumo também em escala industrial. Trata-se de otimizar, ao máximo, tanto a venda como a distribuição e o consumo, o que significa que a produção de 
materiais à distância, como qualquer outra produção industrial, tem que se submeter às leis do consumo: efetividade, facilidade, moda, atração, flexibilidade...

Essas leis de modo algum favorecem os processos educativos; pelo contrário, a cautela e a "impressão falsa", que têm seguido à primeira explosão da educação à distância, são consequiências de se haver confundido a estatística de matrícula e o consumo de materiais de instrução com educação.

\section{Ensino institucionalizado - tanto a} produção de materiais como sua distribuição e consumo exigem que "na educação à distância quem ensina não seja o mestre, mas a instituição que, em termos de organização, está encarregada de cuidar para que a instrução produza-se de forma adequada" (GUTIERREZ; PRIETO, 1994).

É, então, a instituição - com sua complexa engrenagem - a responsável pela operacionalização de mecanismos racionais para a produção intelectual dos insumos, sua produção material e, em seguida, a distribuição. Nessa engrenagem de diferentes grupos especializados, diluem-se ao máximo o estilo pessoal e as relações interpessoais inerentes ao ato educativo.

A existência dos tutores, como reminiscência necessária da relação mestrealuno, forma um apêndice, remendo da modalidade de ensino a distância, que testemunha sua incapacidade de gerar processos educativos. A verdade é que ensino institucional está mais próximo de estilo gerencial do que da comunicação participativa própria dos processos educativos.

4. Ensino autoritário - É próprio de um bom gerente se eficaz em sua função. Isso explica que nos melhores centros de educação a distância, depois de várias décadas de experiência, as exigências empresariais tenham se imposto às demandas educativas. Pior ainda, personagens tão envolvidas na nova modalidade, como é o caso do Dr. John S. Daniel, reitor da Open University em 1994, não tem cerimônia em afirmar que para atender os requisitos institucionais da educação à distância devemos compara-los com os requisitos próprios da logística militar (GUTIERREZ; PRIETO, 1994).

Essa concepção autoritária confirmase no fato de que muitos dos propagandistas da nova modalidade abandonaram a educação presencial por considerá-la pouco eficaz e porque, segundo eles, as linhas de comando e os controles institucionais chegam a se desvirtuar quase por completo.

\section{Ensino massificante - $\mathrm{O}$} funcionamento resulta rentável só quando se alcança uma explicação massiva; isso pela necessidade de baratear com êxito a produção e a distribuição. A criação e a produção de materiais de ensino requerem uma diversidade tão ampla de funcionários que só uma produção em série e massiva pode compensar os custos. 
A produção massiva requererá adaptações permanentes que têm que ver tanto com métodos industriais tradicionais como com protótipos de produções baseados nos modernos e sofisticados processos de informática. A verdade é que universidades com milhares de estudantes marcarão no futuro as pautas a serem seguidos pelos centros de educação a distância menores, sobretudo nos países em desenvolvimento.

E mais ainda, a produção massiva inerente à nova modalidade está despertando um interesse crescente nos programas de cooperação internacional, que estão utilizando, com pouquíssimas adaptações, as produções dos grandes centros de educação a distância já existentes, não importando o país ou a região do planeta em que tenham sido produzidos.

Concluindo, Gutierrez e Prieto (1994) nos lançam uma crítica quanto ao caminho de uma prática mais cautelosa.

$\mathrm{O}$ contraste entre as vantagens e os perigos do modelo revela que a etapa da educação a distância como panacéia dos males de educação está avançando para um entusiasmo mais moderado e realista, que permite crer que, embora "abranja valiosas possibilidades de resolver alguns problemas de educação" (GUTIERREZ; PRIETO, 1994), nem todas são realmente educativas e, portanto, na hora de pô-las em marcha, dever-se-ia pensar muito mais nos usuários do que nas possibilidades e vantagens institucionais.
Os erros cometidos, como também os acertos reais obtidos nas décadas anteriores, devem nos levar a uma prática mais cautelosa que, fundamentada em avaliações menos tradicionais, fomente experiências educativas capazes de dar o maior valor às suas vantagens e possibilidades (GUTIERREZ; PRIETO, 1994).

Vale ressaltar que muitos dos pontos destacados também são características do ensino presencial. O que objetivou-se nesse capítulo foi apenas destacar que a $\mathrm{EaD}$, assim como as demais modalidades de ensino, apresentam riscos e potencialidades, que devem ser observadas e trabalhadas para que a qualidade seja sempre garantida.

\subsection{Legislação}

Nesse tópico serão abordadas as modalidades de $\mathrm{EaD}$ com base na legislação brasileira vigente.

De acordo com o Decreto no 5.622, de 19 de dezembro de 2005, a Educação a distância poderá ser ofertada nos seguintes níveis e modalidades educacionais: Educação básica, educação de jovens e adultos, educação especial (respeitando as especificidades legais pertinentes), educação profissional (técnicos de nível médio e tecnológicos), educação superior (sequenciais, graduação, especialização, mestrado e doutorado) (BRASIL, 2005).

Para um melhor entendimento elas serão brevemente apresentadas a seguir. 
Maior ênfase será dada à Pós-Graduação Lato sensu uma vez que ela é o objeto desse estudo.

A regulamentação que ampara o ensino fundamental e médio pode ser encontrada no capítulo 2, Seção III, Art. 32, $\S 4^{\circ}$.

O Ensino fundamental será presencial, sendo o ensino a distância utilizado como complementação da aprendizagem ou em situações emergenciais. Portaria $\mathrm{N}^{\circ} 301$ de 07 de abril de 1998 (BRASIL, 1998b), Art. $1^{\circ}, \S 1^{\circ}$ :

A instituição de ensino interessada em credenciar-se para oferecer cursos de educação fundamental, dirigidos à educação de jovens e adultos, ensino médio e a educação profissional em nível técnico, deverá apresentar solicitação às autoridades dos respectivos sistemas.

No dia 11 de fevereiro de 1998, o Diário Oficial da União publicava o Decreto $\mathrm{n}^{\mathrm{o}} 2.494$, de 10 de fevereiro de 1998, regulamentando o art. 80 da Lei de Diretrizes e Bases da Educação Nacional (BRASIL, 1998a). Dois meses depois, o Ministro de Estado da Educação e do Desporto assinava a Portaria $\mathrm{n}^{\circ}$ 301, de 7 de abril de 1998, estabelecendo procedimentos de credenciamento de instituições para a oferta de cursos a distância de graduação e de educação profissional tecnológica (BRASIL, 1998b):
Art. $1^{\circ}$ - A instituição de ensino interessada em credenciar-se para oferecer cursos de graduação e educação profissional em nível tecnológico a distância deverá apresentar solicitação ao Ministério da Educação e do Desporto, a ser protocolada no Protocolo Geral do MEC ou na DEMEC da unidade da federação respectiva.

A regulamentação que ampara a Pósgraduação pode ser encontrada no Decreto 5.622, Capítulo V, Art. 24 (Lato sensu) e Art. 25 (Stricto sensu).

\subsection{Controle de Qualidade e Melhoria} Contínua no ensino

Um dos grandes desafios do processo educacional é a elaboração de instrumentos de monitoramento e avaliação para controle qualitativo dos sistemas, tanto presencial, como por EAD.

A melhoria da qualidade da educação é a palavra de ordem na Constituição Federal, competindo essa atribuição ao Governo. Apesar dessa imposição, não existem mecanismos capazes de aferir os níveis de ensino, exceto na pós-graduação, onde a CAPES - Coordenação de Aperfeiçoamento de Pessoal de Ensino Superior - tem uma brilhante experiência nos cursos de mestrado e doutorado (NEVES, 2003). No âmbito da EAD existe o INEP Instituto Nacional de Educação e Pesquisa.

A busca pela qualidade de serviços, particularmente de cursos de graduação e 
pós-graduação deve ser uma preocupação constante da coordenação pedagógica responsável por tais cursos. Em certos casos essa busca é tomada com tanta seriedade que alguns cursos de especialização já conseguiram certificação ISO (QUINTELLA; MELO; LEAL, 2001).

Uma forma de investigar a qualidade de cursos é avaliar o desempenho de suas disciplinas junto aos principais interessados: os estudantes. A avaliação constante dos cursos a distância é de suma importância para a manutenção e melhoria da qualidade (BIELSCHOWSKY, 2006).

A detecção do rol de disciplinas mais e menos preferidas e das variáveis que ajudam a explicar tal preferência é uma maneira intuitiva e eficiente de medir a qualidade atual dos cursos e tomar medidas administrativas para melhorá-la ainda mais, uma vez que a qualidade também pode ser entendida como a satisfação do cliente (DEMING, 1990). No processo ensino aprendizagem o discente é um dos elementos e, este trabalho, se limitará a analisar este aspecto.

Em se tratando de qualidade é preciso observar os objetivos e as várias concepções que alguns autores colocam sobre qualidade.

Para Deming a qualidade deve ter como objetivo as necessidades do usuário presentes e futuros. Já Feigenbaum afirma que o produto ou serviço quando em uso, atenderá as expectativas do cliente. De maneira Geral o termo qualidade pode ser utilizado de suas formas:

1) Conformidade com as exigências: é a capacidade do produto ou serviço satisfazer especificações de determinados clientes aos grupos de clientes.

2) Nível de desempenho satisfazer as especificações e ainda apresentar melhor desempenho em atributos valorizados pelos consumidores.

Já na concepção de Oakland (1994), a qualidade é simplesmente o atendimento as exigências dos clientes. $\mathrm{O}$ autor cita que o fato de atender consistentemente aos requisitos dos clientes pode atingir um diferente nível de satisfação, denominado fascínio do cliente.

Por fim Lai (2003) acrescenta que se torna indispensável entender a definição de qualidade feita pelos clientes para direcionar os esforços organizacionais pretendendo a satisfação do cliente dentro do processo de melhoria contínua. Considera-se de suma importância que todos os funcionários não apenas entendam o significado de qualidade, mas ainda, conheçam as definições dadas pelos clientes para compreender as necessidades de outras áreas funcionais e atingir os requisitos desejados.

Na busca pela satisfação dos clientes, o feedback dos mesmos torna-se de grande importância para a organização. Pode-se então elaborar métodos ou mecanismos para mensurar o nível de satisfação dos clientes em períodos pré-estabelecidos, buscando sempre a melhoria contínua (MIRANDA, 
2005).

Nessa concepção destacamos o ciclo PDCA (Plan, Do, Check, Action) que é um método gerencial, constituído de uma série de atividades com objetivo de melhoramento contínuo. Segundo Imai (1994) o ciclo PDCA começa com um estudo da situação atual, durante o qual os dados são reunidos para uso na formulação de um plano de melhoramento. Uma vez que este plano tenha sido finalizado, é implantado. Depois disso, verifica-se a realização do melhoramento previsto. Quando a experiência tem sucesso, é tomada uma medida final, como a padronização metodológica, para assegurar que os novos métodos introduzidos sejam praticados continuamente para manter o melhoramento. Segundo os conceitos de Imai (1994) e Werkema (1995), o método do PDCA, mostrado na Figura 2, é constituído de quatro etapas bem definidas.

- PLAN significa planejar, estabelecer metas, assim como o método que será usado para alcançá-las. Planejar os melhoramentos das práticas atuais através do uso de ferramentas estatísticas, como as ferramentas da Qualidade.

- DO significa fazer ou executar tudo aquilo que foi planejado anteriormente. Os dados são coletados para análise, tratados $\mathrm{e}$ utilizados na etapa seguinte para verificação da performance do planejado. Para isto é de suma importância a educação, treinamento, a motivação e o comprometimento das pessoas envolvidas no processo.

- CHECK significa checar ou comparar os dados coletados com as metas, verificar se o trabalho resultou no melhoramento desejado.

- ACTION significa atuar, evitar a repetição e institucionalizar o melhoramento como uma nova prática a ser melhorada caso as metas tenham sido atingidas. 


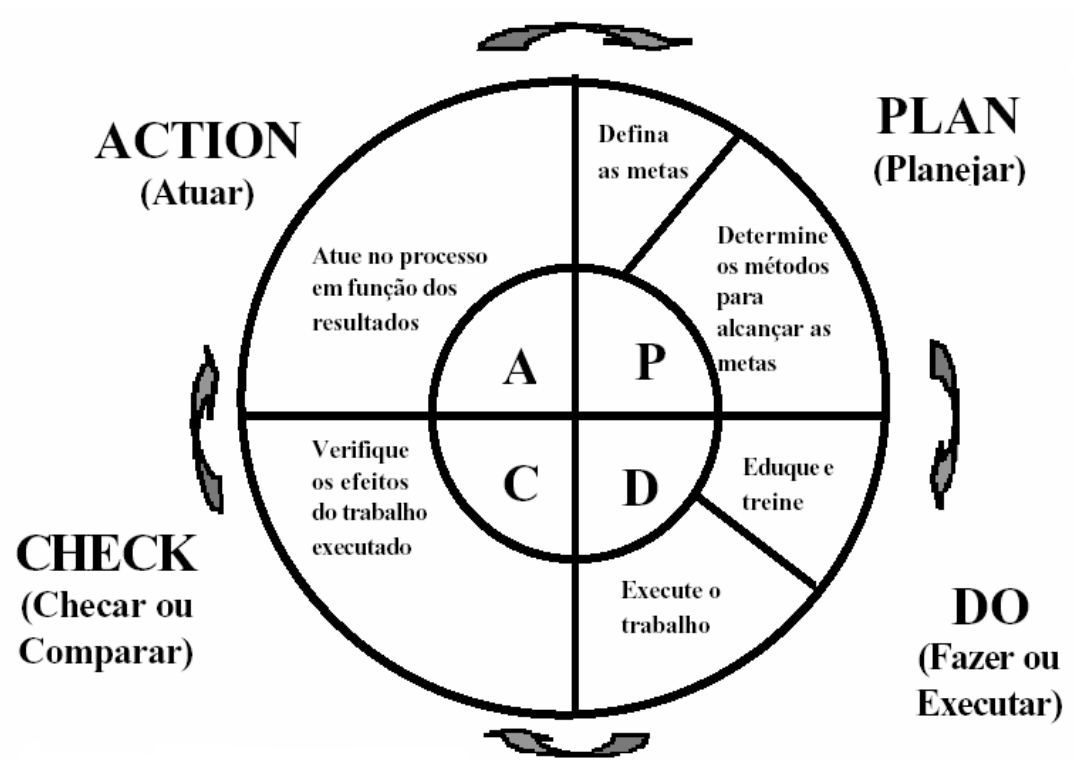

FIGURA 2 Ciclo PDCA (Plan, Do, Check, Action). FONTE: Werkema (1995).

A qualidade na Pós-graduação, em especial na Especialização Lato sensu é de extrema importância uma vez, que para o recredenciamento, as Universidades passam por uma avaliação como consta no Decreto № 2.494, de 10 de Fevereiro de 1998 em seu Art $1^{\circ}$ Parágrafos $4^{\circ}, 5^{\circ}$ e $6^{\circ}$ (BRASIL, 1998a). O ciclo PDCA atua de forma preventiva sendo uma ferramenta importantíssima para a melhoria contínua da qualidade.

Assim este trabalho evidencia a utilização da análise sensorial na educação e abordará alguns de seus aspectos no tópico a seguir.

\subsection{Análise Sensorial na Educação}

A análise sensorial pode ser conceituada como um conjunto de procedimentos que permite que um indivíduo perceba, identifique, pontue e/ou classifique um estímulo externo por meio de um (ou de uma associação) de seus sentidos básicos: olfato, paladar, audição, visão e tato (FERREIRA, 2004). Em outras palavras, a análise sensorial pode ser entendida como o estudo da forma com que um indivíduo percebe (no sentido mais amplo da palavra) um objeto qualquer.

Nessa concepção, o objeto avaliado pode ser uma disciplina. Uma disciplina também é percebida pelos sentidos de uma pessoa, mas não por todos eles. É muito difícil pensar em uma disciplina sendo percebida pelos sentidos do olfato ou paladar. Os sentidos que mais influenciam a forma que a disciplina é percebida são a visão e a audição (principalmente na aula presencial e no ambiente virtual de aprendizagem) e o tato (no contato com o material didático). 
A forma com que uma disciplina é percebida por um estudante pode ser entendida com tendo várias dimensões. Por exemplo, uma das mais importantes dimensões é o que se refere ao docente (sua capacidade de passar uma mensagem de forma clara e convincente, por exemplo). Além disso, as características do material didático, do assunto da disciplina propriamente dito e do comportamento da turma naquela aula, também devem ser avaliados.

Por se ocupar de medir e avaliar aspectos puramente subjetivos, a Análise Sensorial tem relação estreita com a Educação e enorme potencial de contribuir com sua avaliação e monitoramento. Entretanto, isso nunca foi registrado antes na literatura especializada. Vale ressaltar que, embora a Análise Sensorial seja muito mais desenvolvida nas Ciências dos Alimentos, cabe aos pesquisadores da área de Educação a ação multidisciplinar e a exploração de todas as potencialidades das técnicas estatísticas da Sensometria. Um exemplo dessas técnicas é o Mapa de Preferência (SCHLICH, 1995), utilizado aqui no estudo de cursos de Pós-graduação Lato Sensu da área de Administração.

O Mapa de Preferência Externo (MPE) é uma ferramenta estatística multivariada de caráter exploratório, muito usada em Análise Sensorial de alimentos (MINIM, 2006), que tem o objetivo de detectar a preferência de consumidores em um grupo de produtos avaliados, e explicar tal preferência por uma regressão de seus atributos básicos (SCHLICH, 1995). No caso da educação, os consumidores são os discentes.

\section{MATERIAL E MÉTODOS}

\subsection{Metodologia}

Foram analisadas as percepções de discentes de três cursos de Pós-graduação Lato sensu do Departamento de Administração e Economia (DAE) da Universidade Federal de Lavras (UFLA), propondo uma metodologia de monitoramento e avaliação de cursos de Pósgraduação a distância baseada na análise da percepção dos cursos por parte dos discentes, ou seja, baseado em análise sensorial. Tal metodologia prevê o uso de ferramentas estatísticas da Sensometria. Em particular, nesse estudo, utilizou-se o Mapa de Preferência Externo.

\subsection{Os cursos estudados}

Os cursos Administração Rural (ADR), Controladoria e Finanças Empresariais (CFE) e Gerenciamento de Micro e Pequenas empresas (GMP), foram avaliados em seus dois encontros presenciais. Tais cursos foram escolhidos dentre $\mathrm{o}$ conjunto de cursos oferecidos pelo DAE/UFLA por três motivos básicos: i) a Coordenação Pedagógica em questão é 
lotada no DAE/UFLA; ii) esses três cursos estão passando por um processo de reestruturação, e por isso, há necessidade de pautar cientificamente as mudanças a serem feitas; iii) esses cursos seriam oferecidos no período de realização do estudo observacional, primeiro semestre de 2007.

Para atender as exigências do Mapa de Preferência Externo (MPE), foram aplicados questionários ao final de cada encontro presencial. Nesse questionário era perguntada a impressão (preferência) do discente sobre cada uma das disciplinas daquele encontro. $\mathrm{O}$ discente respondia então uma escala hedônica de 9 pontos (variando de 1 - desgostei extremamente a 9 - gostei extremamente). Além disso, para fornecer informação que ajudasse a explicar a preferência, foram usadas 10 covariáveis, que os discentes pontuavam por meio de uma escala não-estruturada de $12 \mathrm{~cm}$, constante do mesmo questionário individual.

As covariáveis avaliadas se dividiam naturalmente em quatro grupos, relativos

i) ao docente: Domínio do conteúdo (DC), Didática (D), Clareza (C), Utilização de Recursos Audio-visuais (URA), Atividade Avaliativa (AAv);

ii)ao material didático impresso: Clareza do Material (CMat) e Redação do Material (RMat); iii) ao assunto propriamente dito: Importância (Im) e Utilidade prática (Ut) do assunto; e

iv) a turma: Participação da turma na disciplina em questão (PT).

Uma recomendação na construção de Mapas de Preferência que é se disponha de muitos consumidores (nesse caso, discentes), por isso, o máximo possível de discentes foi entrevistado. A relação do número de discentes e disciplinas por encontro, por curso é apresentada na Tabela 2. É importante ressaltar que as disciplinas de cada curso foram numeradas de 1 ao número máximo, em cada curso e cada encontro, para manter o anonimato do docente. Portanto, por exemplo, a disciplina 2 do primeiro encontro de um curso não tem nada a ver com a disciplina 2 de outro encontro ou outro curso. As comparações devem ser feitas apenas dentro de uma combinação curso $x$ encontro.

Vale ressaltar que os dois encontros presenciais foram analisados separadamente porque os discentes neles matriculados não eram os mesmos, sendo esta uma exigência do Mapa de Preferência. Todas as análises foram feitas no software $R$ versão 3.0.1 ( $R$ CORE TEAM, 2013). 
TABELA 1 Relação do número de discentes e disciplinas nos dois encontros de cada curso analisado.

Curso Encontro Número de discentes Número de disciplinas

\begin{tabular}{lccc}
\hline \multirow{2}{*}{ ADR } & I & 26 & 8 \\
\cline { 2 - 4 } & II & 38 & 8 \\
\hline \multirow{2}{*}{ CFE } & I & 44 & 5 \\
\cline { 2 - 4 } & II & 48 & 4 \\
\hline \multirow{2}{*}{ GMP } & I & 20 & 6 \\
\cline { 2 - 4 } & II & 26 & 7 \\
\hline
\end{tabular}

\section{RESULTADOS E DISCUSSÃO}

\subsection{Cursos estudados}

\section{a) Administração Rural (ADR)}

A segunda linha da Figura 6 mostra os Mapas de Preferência para os dois encontros do curso ADR. Em cada um dos encontros foram ofertadas oito disciplinas distintas. Nesses mapas, é possível perceber que as curvas de nível que se situam à direita mostram grande densidade de estudantes, ou seja, essa é a região onde estão localizadas aquelas disciplinas que a maioria dos estudantes prefere.

No mapa do primeiro encontro, percebe-se que as disciplinas 4 e 8 são as preferidas, seguidas pelas disciplinas 2, 7, 1 e 3 , respectivamente. Entretanto, as disciplinas 6 e 5 são as menos apreciadas pelos estudantes. Note que isso não significa que elas não sejam boas, apenas não são preferidas quando comparadas com as outras seis disciplinas em questão. As disciplinas de pior desempenho (5 e 6) devem sofrer intervenções da Coordenação Pedagógica do curso. Apesar de se situarem no conceito Gostei ligeiramente, pelo menos estão na região de aceitação da escala.

Já no mapa do segundo encontro (à direita), as disciplinas 7 e 8 são as preferidas pelos estudantes, seguidas imediatamente pelas disciplinas 4, 1, 3, 2 e 6 . A disciplina 5 foi considerada a menos preferida. Pode-se ver no Quadro 3, que esta disciplina teve preferência média de 4,6, ou seja, entre Desgostei ligeiramente e Indiferente. Essa disciplina teve média abaixo do esperado porque houve uma divergência de ideologias entre o docente e alguns discentes durante a aula presencial.

A compreensão dos mapas só fica completa quando se observa a primeira linha da Figura 6.

Os gráficos nesta linha mostram as covariáveis que ajudam a explicar a preferência. Praticamente todas elas estão orientadas para o lado positivo do eixo $\mathrm{x}$. Porém, algumas variáveis diferenciam as disciplinas na segunda dimensão (eixo y). Por exemplo, no primeiro encontro, as disciplinas 5 e 6 , embora não sendo 
preferidas, podem ser diferenciadas.

O docente da disciplina 5 parece ter considerado e maior importância (Imp) e utilidade prática $(\mathrm{Ut})$.

mais clareza (C) e o assunto da disciplina 6 é

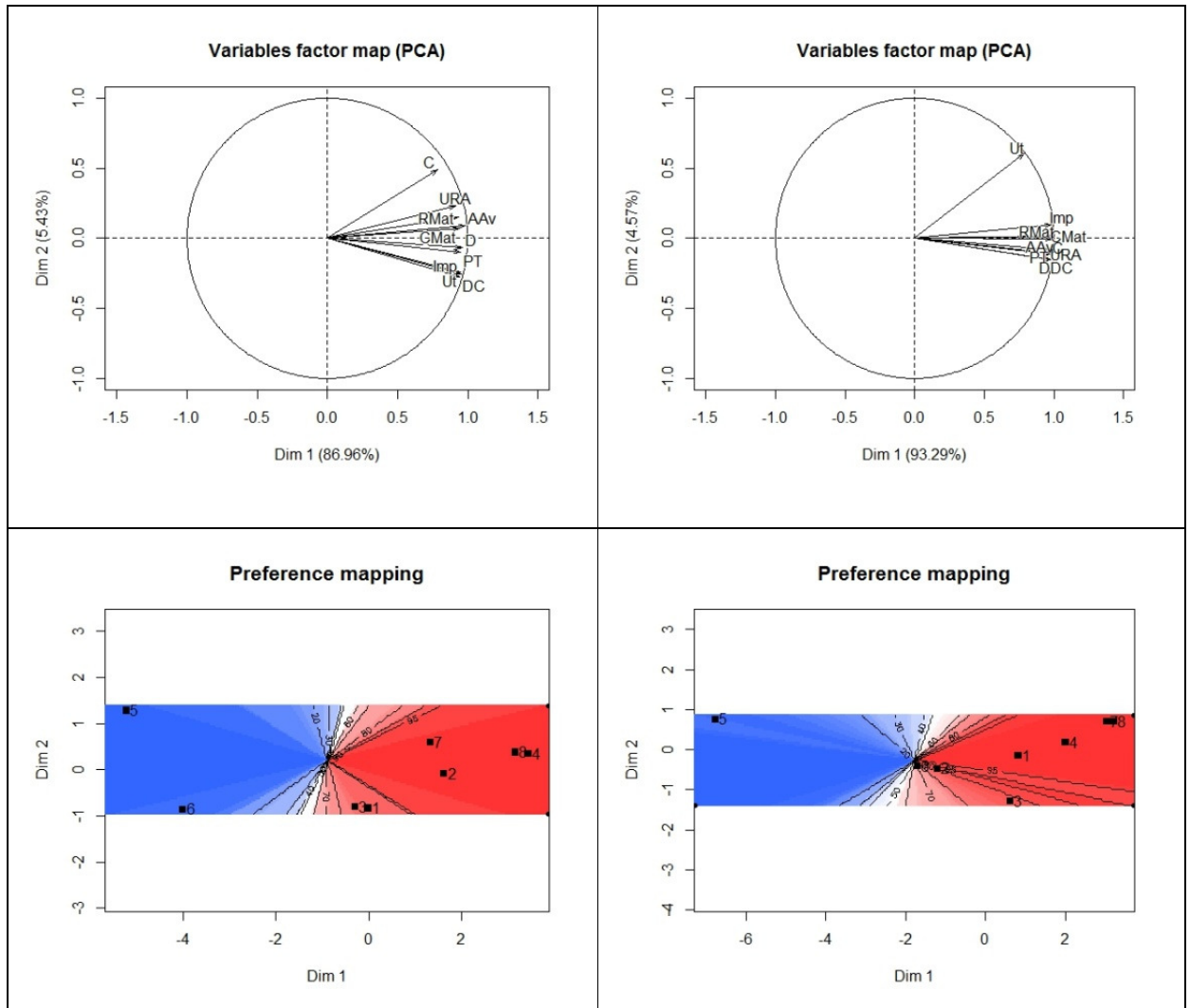

FIGURA 3 Covariáveis explicativas (linha 1) e Mapa de Preferência Externo (linha 2) para o curso ADR, nos encontros 1 e 2 (coluna da esquerda e da direita, respectivamente).

QUADRO 1 Relação de disciplinas e médias de preferência do primeiro e segundo encontro do curso ADR.

\begin{tabular}{|c|c|c|c|c|c|c|c|c|}
\hline ADR I & $\mathbf{8}$ & $\mathbf{2}$ & $\mathbf{4}$ & $\mathbf{1}$ & $\mathbf{7}$ & $\mathbf{3}$ & $\mathbf{6}$ & $\mathbf{5}$ \\
\hline Média & 8,7 & 8,7 & 8,6 & 8,2 & 8,1 & 7,7 & 6,0 & 6,0 \\
\hline
\end{tabular}

\begin{tabular}{cccc}
$\mathbf{9}$ & $\mathbf{8}$ & $\mathbf{7}$ & $\mathbf{6}$ \\
\hline Gostei & Gostei & Gostei & Gostei \\
extremamente & muito & moderadamente & ligeiramente
\end{tabular}

\begin{tabular}{|c|c|c|c|c|c|c|c|c|}
\hline ADR II & $\mathbf{7}$ & $\mathbf{4}$ & $\mathbf{8}$ & $\mathbf{1}$ & $\mathbf{3}$ & $\mathbf{2}$ & $\mathbf{6}$ & $\mathbf{5}$ \\
\hline Média & 8,5 & 8,3 & 8,3 & 8,0 & 7,9 & 7,1 & 6,9 & 4,6 \\
\hline
\end{tabular}

\begin{tabular}{cccccc}
$\mathbf{9}$ & $\mathbf{8}$ & $\mathbf{7}$ & $\mathbf{6}$ & $\mathbf{5}$ & $\mathbf{4}$ \\
\hline Gostei & Gostei & Gostei & Gostei & Indiferente & Desgostei \\
extremamente & muito & moderadamente & ligeiramente & & ligeiramente
\end{tabular}


Nos dois encontros desse curso, um par de disciplinas teve o melhor desempenho (8 e 4, primeiro encontro; e 7 e 8 , no segundo). É interessante ressaltar que as disciplinas 8,4 e 7 são ministradas pelo mesmo docente, o que merece o reconhecimento da parte da Coordenação Pedagógica.

Das dezesseis disciplinas avaliadas nesse curso, 9 situaram-se entre os conceitos Gostei muito e Gostei extremamente (entre 8 e 9 pontos na escala hedônica). Esse conceito deve ser perseguido pelas demais disciplinas, como resultado de ações corretivas tomadas pela Coordenação Pedagógica.

\section{b) Controladoria e Finanças Empresariais (CFE)}

A segunda linha da Figura 7 mostra os Mapas de Preferência para os dois encontros do curso CFE. No primeiro encontro foram analisadas cinco disciplinas e no segundo encontro, quatro. No mapa do primeiro encontro, é possível perceber que as curvas de nível que se situam para cima mostram grande densidade de estudantes, ou seja, essa é a região onde estão localizadas aquelas disciplinas que a maioria dos estudantes prefere. No segundo encontro esse mesmo comportamento acontece à direita.

No mapa do primeiro encontro, percebe-se que as disciplinas 5, 1, 3 e 4 são as preferidas, seguida pela 2, que é a menos apreciada pelos estudantes. A disciplina de pior desempenho (2) se situa entre as classes
Indiferente e Gostei Ligeiramente, o que é uma média muito baixa em relação ao que o curso deve alcançar.

Já no mapa do segundo encontro (à direita), as disciplinas 1 e 3 são as preferidas pelos estudantes, seguidas imediatamente pelas disciplinas 2 e 4 . A disciplina 2 foi considerada a menos preferida. Pode-se ver no Quadro 4, que esta disciplina teve preferência média de 5,6, ou seja, entre Desgostei ligeiramente e Indiferente, que também é uma média muito aquém da esperada para o curso.

Analisando o gráfico das covariáveis (primeira linha da tabela sete) é relevante observar que a disciplina 1 do primeiro encontro, mesmo não tendo a maior média de preferência, se destaca pelo domínio do conteúdo (DC) por parte do docente respionsável. Já no segundo encontro, a disciplina 2 é menos preferida que a disciplina 4, entretanto pelo fato de estar para baixo do eixo $\mathrm{x}$ ela é caracterizada pela participação da turma (PT) e importância do conteúdo (Imp).

Das nove disciplinas avaliadas nesse curso, 5 situaram-se entre os conceitos Gostei muito e Gostei extremamente. Portanto, as demais devem ser acompanhadas pela coordenação pedagógica para que atinjam a meta estabelecida pelo curso. 


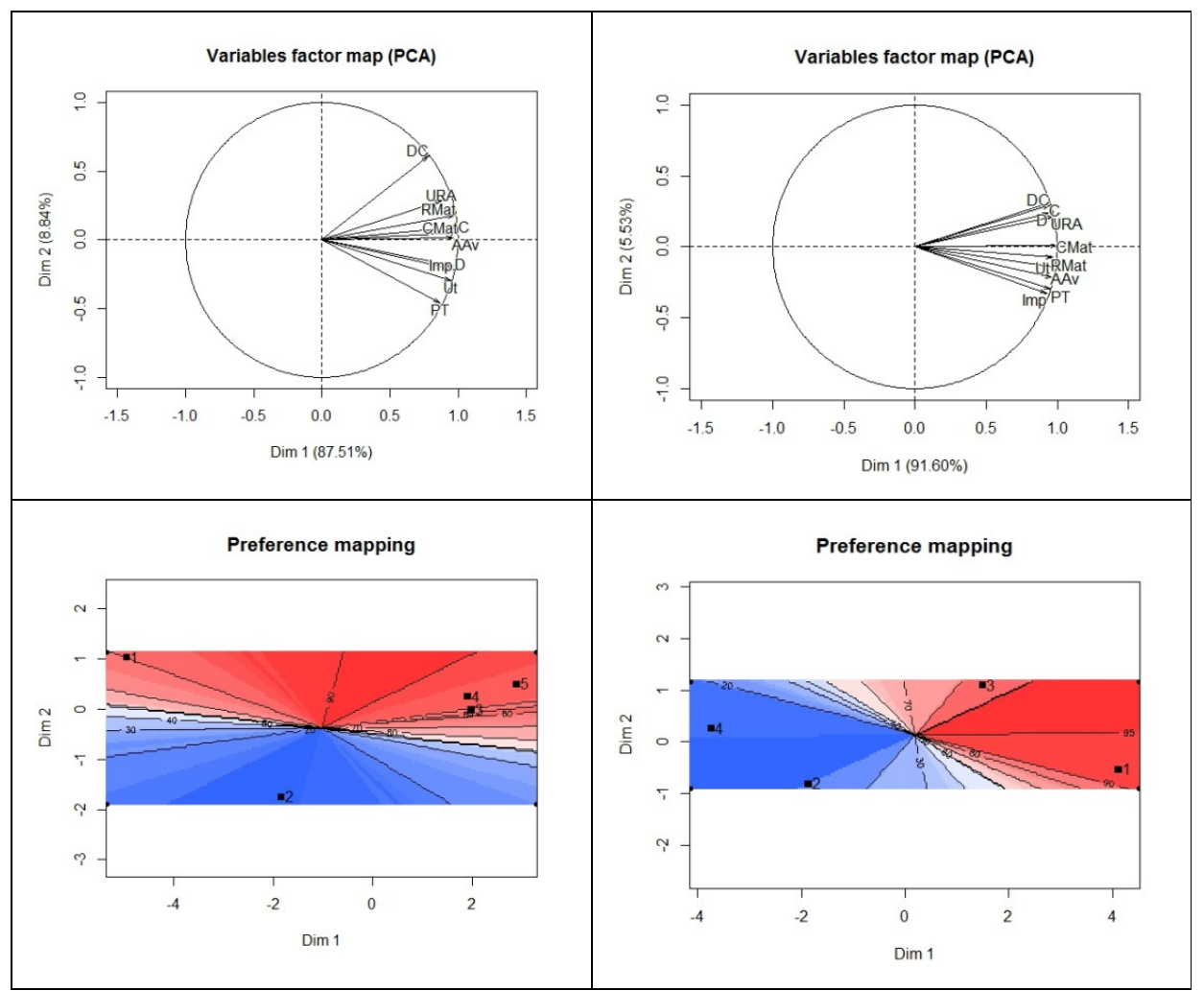

FIGURA 4 Covariáveis explicativas (linha 1) e mapa de preferência externo (linha 2) para o curso CFE, nos encontros 1 e 2 (coluna da esquerda e da direita, respectivamente).

QUADRO 2 Relação de disciplinas e médias de preferência do primeiro e segundo encontro do curso CFE.

\begin{tabular}{|c|c|c|c|c|c|}
\hline CFE I & $\mathbf{5}$ & $\mathbf{1}$ & $\mathbf{3}$ & $\mathbf{4}$ & $\mathbf{2}$ \\
\hline Média & 8,3 & 8,2 & 8,1 & 8,1 & 6,9 \\
\hline
\end{tabular}

\begin{tabular}{cccc}
$\mathbf{9}$ & $\mathbf{8}$ & $\mathbf{7}$ & $\mathbf{6}$ \\
\hline Gostei & Gostei & Gostei & Gostei \\
extremamente & muito & moderadamente & ligeiramente
\end{tabular}

\begin{tabular}{|c|c|c|c|c|}
\hline CFE II & $\mathbf{1}$ & $\mathbf{3}$ & $\mathbf{4}$ & $\mathbf{2}$ \\
\hline Média & 8,3 & 7,4 & 6,2 & 5,6 \\
\hline
\end{tabular}

\begin{tabular}{ccccc}
$\mathbf{9}$ & $\mathbf{8}$ & $\mathbf{7}$ & $\mathbf{6}$ & $\mathbf{5}$ \\
\hline Gostei & Gostei & Gostei & Gostei & Indiferente \\
extremamente & Muito & moderadamente & ligeiramente &
\end{tabular}


Pedagógica.

\section{c) Gerenciamento de Micro e Pequenas empresas (GMP):}

A segunda linha da Figura 8 mostra os Mapas de Preferência para os dois encontros do curso GMP. No primeiro encontro foram analisadas seis disciplinas e no segundo encontro, sete. Nos mapas, é possível perceber que as curvas de nível que se situam para direita mostram grande densidade de estudantes, ou seja, essa é a região onde estão localizadas aquelas disciplinas que a maioria dos estudantes prefere.

No mapa do primeiro encontro, percebe-se que a disciplina 3 é a preferida, seguida pelas disciplinas 5, 2, 4, e 1 . Sendo a 6 menos apreciada pelos estudantes. A disciplina de pior desempenho (6) se situa entre as classes Indiferente e Gostei Ligeiramente, sendo uma média muito baixa em relação ao que o curso deve alcançar.

Já no mapa do segundo encontro (à direita), as disciplinas 3 e 6 são as preferidas pelos estudantes, seguidas imediatamente pelas disciplinas 7, 4 e 5. As disciplinas 2 e 1 foram consideradas as menos preferidas. Pode-se ver no Quadro 5, que as disciplinas 1 e 2 tiveram médias de 3,7 e 4,7 respectivamente, ficando situadas na região de rejeição (desgostei). A disciplina 1 apresentou pior desempenhos perante as demais disciplinas dos demais cursos analisados no estudo, uma questão de preocupação para a Coordenação
Analisando o gráfico das covariáveis (primeira linha da tabela sete) é relevante observar que a disciplina 6 do primeiro encontro mesmo tendo a menor média de preferência, se destaca pela utilização de recursos audiovisuais (URA), o que mostra que a utilização de muitos recursos não é sinônimo de uma boa aula. Já no segundo encontro, embora a disciplina 1 seja menos preferida que a disciplina 2, ela apresenta mais domínio do conteúdo (DC) por parte do docente, o que é um ponto extremamente importante na ministração de aula, mas não foi o suficiente para que ela fosse bem avaliada.

Das treze disciplinas avaliadas nesse curso, apenas três situaram-se entre os conceitos Gostei muito e Gostei extremamente. Portanto, o curso foi, no geral, o pior avaliado nesse estudo. Por esse motivo a Coordenação Pedagógica deve dar uma atenção especial a esse curso. 


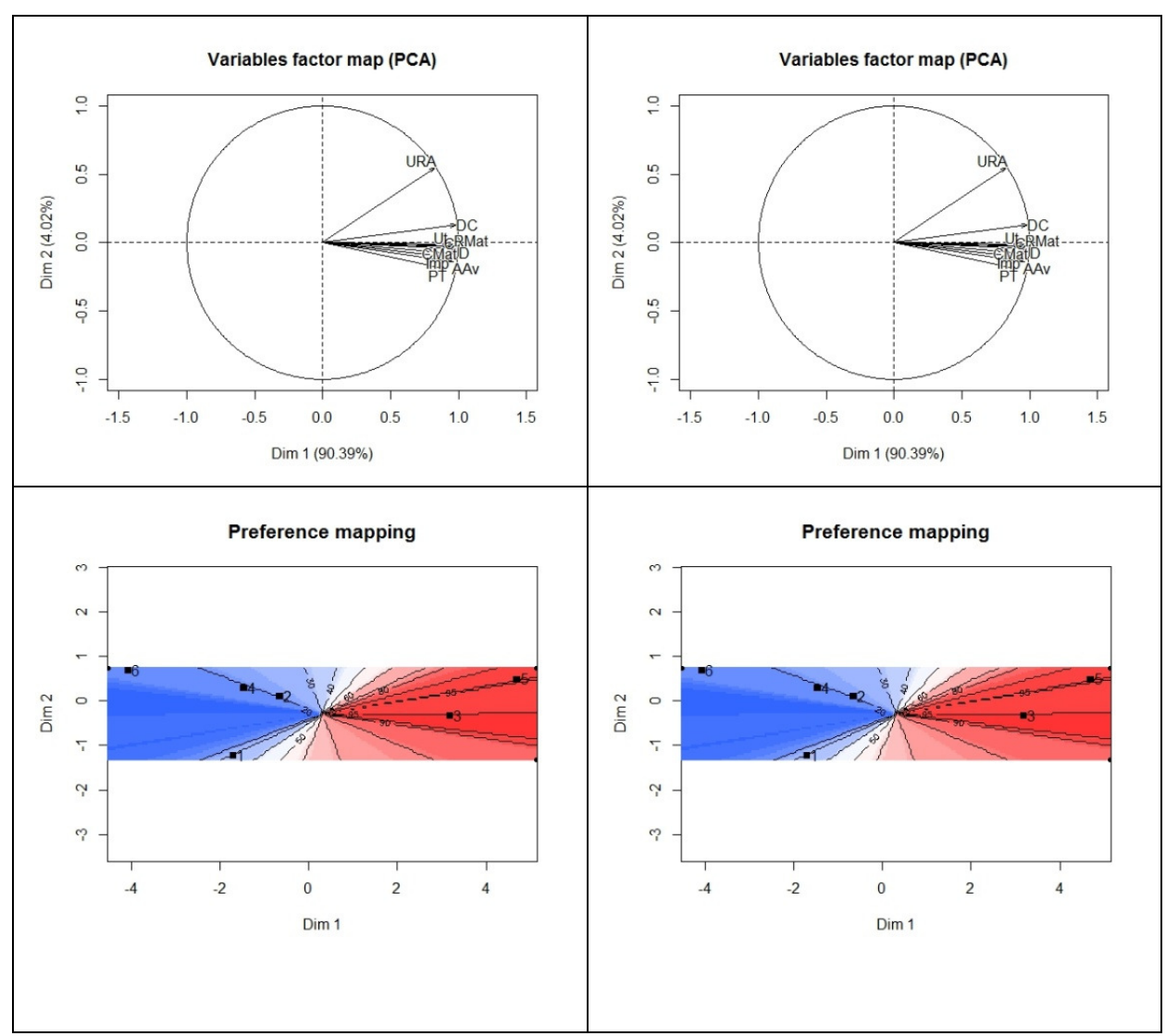

FIGURA 5 Covariáveis explicativas (linha 1) e mapa de preferência externo (linha 2) para o curso GMP, nos encontros 1 e 2 (coluna da esquerda e da direita, respectivamente).

QUADRO 3 Relação de disciplinas e médias de preferência do primeiro e segundo encontro do curso GMP.

\begin{tabular}{|c|c|c|c|c|c|c|}
\hline GMP I & $\mathbf{3}$ & $\mathbf{5}$ & $\mathbf{2}$ & $\mathbf{4}$ & $\mathbf{1}$ & $\mathbf{6}$ \\
\hline Média & 8,51 & 7,96 & 7,69 & 7,21 & 7,09 & 5,72 \\
\hline
\end{tabular}

\begin{tabular}{ccccc}
$\mathbf{9}$ & $\mathbf{8}$ & $\mathbf{7}$ & $\mathbf{6}$ & $\mathbf{5}$ \\
\hline Gostei & Gostei & Gostei & Gostei & Indiferente \\
extremamente & muito & moderadamente & ligeiramente &
\end{tabular}

\begin{tabular}{|c|c|c|c|c|c|c|c|}
\hline GMP II & $\mathbf{3}$ & $\mathbf{6}$ & $\mathbf{7}$ & $\mathbf{4}$ & $\mathbf{5}$ & $\mathbf{2}$ & $\mathbf{1}$ \\
\hline Média & 8,5 & 8,0 & 7,4 & 7,2 & 7,1 & 4,7 & 3,7 \\
\hline
\end{tabular}

\begin{tabular}{ccccccc}
$\mathbf{9}$ & $\mathbf{8}$ & $\mathbf{7}$ & $\mathbf{6}$ & $\mathbf{5}$ & $\mathbf{4}$ & $\mathbf{3}$ \\
\hline Gostei & Gostei & Gostei & Gostei & Indiferente & Desgostei & Desgostei \\
extremament & muito & moderadament & ligeirament & & ligeirament & moderadamente \\
$\mathrm{e}$ & & $\mathrm{e}$ & $\mathrm{e}$ & & $\mathrm{e}$ &
\end{tabular}


3.2 Proposta de Monitoramento e Avaliação

Especificamente, no caso de uma Coordenação pedagógica responsável por tais cursos de Pós-graduação Lato sensu, as quatro fases do ciclo PDCA, visando à melhoria contínua, podem ser interpretadas da forma apresentada na Tabela 2

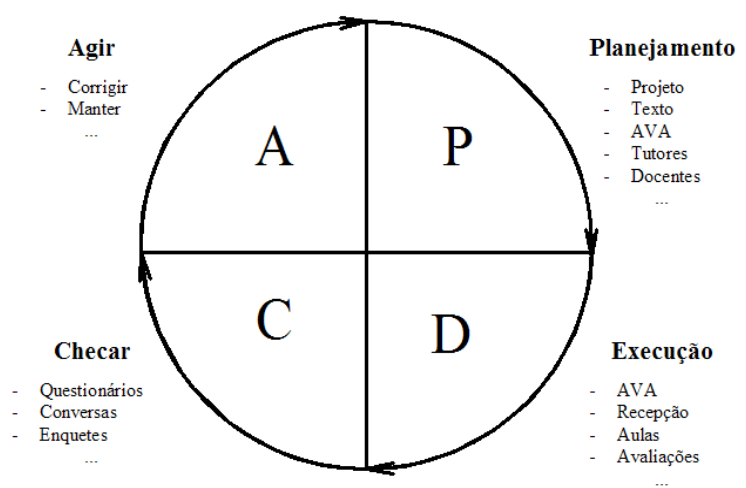

FIGURA 6 Ciclo PDCA adaptado para o monitoramento e avaliação de cursos Lato sensu a distancia pela sua Coordenação Pedagógica.

\section{Uma forma esquemática} pode ser mais facilmente compreendida, para isso a Figura 4 pode ser consultada. Ela traz a mesma interpretação de forma resumida. Vale, entretanto, notar que a melhor representação esquemática da Melhoria Contínua deveria ser feita por uma espiral, e não por um círculo. A idéia aqui é que o ciclo de melhorias se repita indefinidamente e, naturalmente, esperase que o ponto de partida da segunda volta (por exemplo) seja de um ponto superior ao ponto de partida da primeira volta.

TABELA 2 Interpretação do ciclo PDCA por uma Coordenação pedagógica responsável pelo monitoramento e avaliação de cursos de Pós-graduação Lato sensu.

Projetos, textos acadêmicos de qualidade, do Ambiente Virtual de Planejamento Aprendizagem (AVA), escolha e capacitação de tutores e docentes, atividades, horários, recepção de alunos, atendimento, espaço físico, avaliações, lista de presença, aulas.

Execução Primeiro contato com os estudantes pelo AVA, recepção dos estudantes nos encontros presenciais, ministração de aulas, visitas e avaliações.

Checagem Por meio de questionários, conversas, enquetes.

Ação Manter e corrigir


O modelo de monitoramento e avaliação de cursos baseado em análise sensória será apresentado em forma de passos a serem seguidos.

\subsection{Monitoramento e avaliação de} cursos Baseado em Análise Sensorial

1. Planejar o curso;

2. Executar o curso;

3. Aplicar questionários para detectar a preferência dos discentes pelas disciplinas (Escala Hedônica) e medir covariáveis que ajudem a explicar tal preferência;

4. Analisar os dados por meio de uma ferramenta da Sensometria (por exemplo, o Mapa de Preferência);

5. Interpretar os resultados identificando os pontos a serem mantidos (positivos) e os a serem corrigidos (negativos). Deve-se perseguir uma nota entre oito e nove em todas as disciplinas do curso;
6. Ação da coordenação pedagógica junto a docentes, material didático; secretárias entre outros que mereçam atenção;

7. Planejamento do Projeto do curso reformulado, executando novamente os passos a partir do passo 2 .

O Mapa de Preferência é apenas uma das ferramentas da Sensometria, que pode ser definida como o conjunto de métodos estatísticos aplicados a Análise Sensorial. Ele foi destacado nesse trabalho por ter sido a ferramenta escolhida para analisar o caso real em estudo. Entretanto, a proposta de gestão de cursos baseada em Análise Sensorial admite qualquer outra ferramenta da Sensometria para medir a percepção do curso pelos discentes e posterior tomada de decisões, visando a melhoria contínua da qualidade (Figura $5)$.

\section{Curso}

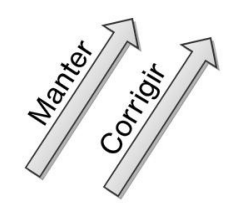

\section{Percepção Sensometria Discente}

FIGURA 7 Esquema da sugestão de dinâmica da gestão de cursos baseada em Análise Sensorial. 


\section{CONCLUSÃO}

A Educação a Distância é uma modalidade de ensino atual, em consonância com os dias atuais e que deve ser tratada com seriedade e responsabilidade. No Brasil, grandes incentivos governamentais vêm sendo dados a essa modalidade, portanto a tendência é o crescimento e a difusão, uma vez que ela é uma política de democratização do ensino. Conclui-se que esse crescimento deve estar sempre associado à qualidade para que a própria modalidade não caia no descrédito com o passar do tempo.

Conclui-se também que é possível que a Coordenação Pedagógica de cursos de EaD utilize ferramentas da sensometria para fazer a gestão de cursos a distância baseada em Análise Sensorial, ou seja, na percepção dos cursos pelos discentes. Esse tipo de gestão permite a manutenção de aspectos positivos e a correção de pontos negativos dos cursos, propiciando a melhoria contínua da qualidade.

\begin{tabular}{llr}
\multicolumn{2}{c}{ Especificamente nos cursos } \\
estudados, conclui-se que a \\
Administração & Rural e Controladoria e
\end{tabular}
Finanças Empresariais apresentaram desempenho satisfatório, tendo apenas algumas disciplinas fora da meta préestabelecida pela coordenação. $O$ curso Gerenciamento de Micro e Pequenas
Empresas apresentou um desempenho muito abaixo do esperado e deve ser objeto de estudo, dedicação e atenção da Coordenação Pedagógica.

\section{Referências Bibliográficas}

\section{BIELSCHOWSKY, C. E. Educação}

superior a distância: uma estratégia para avaliação institucional. In: SEED-

MEC. em Desafios da educação a distância na formação de professores. Brasilia: Secretaria de Educação a

Distância, 2006. 237p.

\section{BRASIL. MINISTÉRIO DA}

EDUCAÇÃO. Decreto n. ${ }^{\mathbf{2}} \mathbf{2 . 4 9 4}$, de 10 de fevereiro de 1998a. Disponível em: $<$ http://portal.mec.gov.br/seed/arquivos/p df/tvescola/leis/D2494.pdf>. Acesso em: 7 jul./2008.

\section{BRASIL. MINISTÉRIO DA}

EDUCAÇÃO. Portaria n. ${ }^{\circ}$ 301, de 07 de abril de 1998b. Disponível em: < http://portal.mec.gov.br/seed/arquivos/pdf /tvescola/leis/port301.pdf>. Acesso em: 12 jun./2008.

\section{BRASIL. MINISTÉRIO DA} EDUCAÇÃO. Decreto n. ${ }^{\circ} \mathbf{5 . 6 2 2}$, de 20 de dezembro de 2005. Disponível em: $<$ http://portal.mec.gov.br/seed/arquivos/p 
df/dec_5622.pdf>. Acesso em: 10

jul./2008.

DEMING, W.E. Qualidade: a revolução

da administração. Rio de Janeiro: Ed.

Marques Saraiva S.A. 1990. 367p.

FERREIRA, E. B. Análise Gerenalizada

de Procrustes via R: uma aplicação em

laticínios. Lavras: UFLA. 2004. 115p.

(Dissertação de mestrado).

GUTIÉRREZ, F.; PRIETO, D. A

mediação pedagógica educação a

distância alternativa. Campinas, SP:

Papirus. Série Educação Internacional do Instituto Paulo Freire. 1994. 165p.

IMAI, M. KAIZEN A Estratégia para o sucesso competitivo. 5. ed., São Paulo: IMAM, 1994. 236 p.

LAI, K.A. Market Orientation in Qualit Oriented Organizations and its Impact on their performance. International Journal of Production Economics. Hong Kong. V. 84 p17-34. 2003.

MARQUES, C. Ensino a distância começou com cartas a agricultores.

Folha on-line. 2004. Acesso em:

30/04/2007. Disponível em:

$<$ www.folha.com.br>.
MINIM, V. P. R. Análise Sensorial:

estudos com consumidores. Viçosa: Ed.

da Universidade Federal de Viçosa.

2006.225p.

MIRANDA, J. B. D. Busca da satisfação dos clientes externos através da análise dos resultados dos atributos da qualidade: Uma aplicação na indústria de auto peças. Campinas: $\mathrm{Ed}$.

UNICAMP. 2005.158p.

MUNDIM, K. C. Ensino a Distância no Brasil: problemas e desafios. In: SEEDMEC. Desafios da Educação a Distância na formação de professores. Brasília: Secretaria da Educação a distância. 2006. $237 p$.

NEVES, C. M.C. Referenciais de qualidade para cursos a distância.

Ministério da Educação. Secretaria de Educação a Distância. 2003. 16p.

Disponível em:

$<$ http://portal.mec.gov.br/seed/>. Acesso em: 30 de abril de 2007.

OAKLAND, J.S. Gerenciamento da Qualidade Total. São Paulo: Ed. Nobel. 1994.

QUINTELLA, R. H.; MELO, V. P.; LEAL, R. Qualidade em serviços 
educacionais: o caso da certificação

ISSO 9002 do curso de especialização

em Administração da UFBA. ANPAD.

2001. Acesso em: 19 de abril de 2007.

Disponível em:

$<$ http://www.serprofessoruniversitario.pro

.br/imprimir.php?modulo=17\\&t>.

R Core Team. R: A language and

environment for statistical computing.

R Foundation for Statistical Computing.

Viernna, Áustria. 20013.

SANTOS, A. I. dos. A Universidade

Aberta Britânica: aberta a pessoas,

lugares, métodos e idéias. In: SEED-

MEC. Desafios da Educação a Distância

na formação de professores. Brasília:

Secretaria da Educação a distância. 2006.

$237 \mathrm{p}$.

SCHLICH, P.Preference mapping:

relating consumer preferences to sensory or instrumental measurements.

In: ETIEVANT, P.; SCHREIER, P.

Bioflavour 95: analysis/precursor

studies/biotechnology, 2 ed., Orlando -

Flórida: Academic Press, Inc., 1993.

$338 \mathrm{p}$.

WERKEMA, M.C.C. As ferramentas da

qualidade no gerenciamento de

processos. 3. ed., Belo Horizonte:
Fundação Christiano Ottoni, v. 1, 1995.

$108 \mathrm{p}$. 